\title{
Revitalizing the Concept of Vocabulary Teaching in Professional Education
}

\author{
Babi Duli, Laxmi Ramana \\ Department of English, Anurag University, Venkatapur, Ghatkesar, Hyderabad, India \\ Email address: \\ babihs@anurag.edu.in (B. Duli), laxmiramanahs@anurag.edu.in (L. Ramana)

\section{To cite this article:} \\ Babi Duli, Laxmi Ramana. Revitalizing the Concept of Vocabulary Teaching in Professional Education. International Journal of Language \\ and Linguistics. Vol. 9, No. 3, 2021, pp. 92-99. doi: 10.11648/j.ijl1.20210903.14
}

Received: February 16, 2021; Accepted: March 19, 2021; Published: May 26, 2021

\begin{abstract}
The vocabulary of the English language is compartmentalized in professional degree courses like Engineering, Medical, Law, Pharmaceutical, Arts etc. Due to this the professionals are unable to express themselves convincingly. In due course of the time they become handicapped to use the universal vocabulary related to the field of others and building the gap between industry and academia. The industry is in need of the professionals who can speak to the globe. Because of this limited vocabulary, as the authors are working in the professional colleges observed, that there is a miserable failure when a general topic is given to express. Though the professionals are good at academics fail to express their thought process in an open forum due to lack of vocabulary. It is also observed that the so-called examination system will examine their retention power instead of testing their general ability. The academia on the other hand will not concentrate on universal vocabulary since it is pestered with curriculum and syllabus design. The aspiring students who want to go abroad are struggling to get through the Basic English tests. Since the Common European Framework Reference (CEFR) put some standards in the English language proficiency levels to be recognized globally, the professionals understood the importance of expression. Here exactly the professionals face the building blocks. Though the professionals selected through campus recruitments, feel difficulty to communicate effectively. To reason, the reasons are many to speak on. Hence, the paper is going to address the challenges involved in.
\end{abstract}

Keywords: Technical, Scientific, General, Vocabulary - Proficiency Tests-reasons

\section{Introduction}

Today the professional education is everyone's choice but the competence levels and proficiency levels do not match accordingly. The challenges of a teacher in Higher Education are more, especially those, who teach to the professional students. The expectations of the stakeholders are high and demand that their wards should have an offer/appointment letter while leaving the campus. The professionals do not show interest in attending the class for various reasons. The Industry does not convince with the language proficiency of these professionals at the time of interview. The researchers try to find out the reasons and give proven strategies for the teachers to inculcate interest and involve the students in classroom learning. The vocabulary that they have been acquiring since their schooling is completely different when they join corporate sector. Once they join the corporate, the buzz words confuse them because during their professional education, they didn't come across or studied or taught. The problem arises when conceptual lingo remains just that: conceptual. A word loses its meaning and becomes simply rhetoric, no longer rooted in anything tangible. Even worse, when business and marketing jargon are transferred from one company to the next, irrespective of differences in operations, products or culture, words take on incompatible or conflicting definitions.

Insufficient academic vocabulary knowledge has also been strongly associated with the oft-cited 'gap' in academic achievement that exists between certain groups of studentsprimarily the economically disadvantaged and English language learners - and their grade-level peers. Many of the meaning problems are caused by the fact that 'word family' does not consider grammatical parts of speech (e.g. nouns, verbs, adjectives, adverbs), as we can see when we analyze a typical word like, "Proceed". Proceed (verb), Proceeds (Noun or Verb), Proceeding (Verb), and Proceedings (Noun). 
Consider, for example, the differences in primary meanings between react (respond), reactionary (strongly opposed to social or political change), reactivation (to make something happen again), and reactor (a device or apparatus). These meaning differences are accentuated further as members of word families cross over the various academic disciplines. [9-19].

Since the English language has attained the global status, everyone is forced to cobble together his language ability with a level of accuracy that transfers meaning in production and comprehension. By the 1990's, the idea of developing a CEFR was launched in 1991 to test the language proficiency.
It aims at developing a comprehensive framework for language learning, teaching and assessment in general. The descriptors scaled by the CEFR are common for all. The students who get through these tests are recognized globally. Now it has become the need of the hour to be tested and proved according to the CEFR Proficiency levels. Apart from the content vocabulary, the professionals are required to develop language proficiency in general.

The Common Core Standards use the research of Isabel Beck and Margaret Mc Keown to categorize words into Tier One, Two and Three. Here is how the Standards describe Tiers:

Table 1. Word Tiers according to Beck \& Mc Keown.

\begin{tabular}{lll}
\hline S. No & Words & Examples \\
\hline 1. & $\begin{array}{l}\text { Tier-1: Words of everyday speech. Very simple and easy to use words. Learnt } \\
\text { since we join the school } \\
\text { Tier-2: These are high-frequency words for mature language users. These }\end{array}$ & $\begin{array}{l}\text { Ask, big, cut, do, eat, fat, go, join, know, like, mix, neat, out, } \\
\text { put, quick, run, seat, talk, etc }\end{array}$ \\
$\begin{array}{l}\text { words are found generally in written contexts and are particularly powerful } \\
\text { because of their wide applicability to many sorts of reading }\end{array}$ & $\begin{array}{l}\text { Fortunate, masterpiece, obscure, opportunist, industrious, } \\
\text { benevolent, malicious, }\end{array}$ \\
3. & $\begin{array}{l}\text { Tier-3: These words are content -based and content-specific and will be taught } \\
\text { as a part of teaching content. }\end{array}$ & $\begin{array}{l}\text { Deposition, erosion, meander, lava, magma, isthmus, } \\
\text { peninsula, and cape }\end{array}$ \\
\hline
\end{tabular}

\section{Literature Reviews}

So far the research is taken place on the vocabulary limited to know the size of the vocabulary that a university students should have. In the article "The Vocabulary

Knowledge of University Students in Saudi Arabia" by Ahmed Al-Masrai, Swansea University, UK and James Milton Swansea University, UK, tried to prove that the university students vocabulary size needs to enhanced. Two tests were used to measure the participants' vocabulary size: the well-established Euro centric Vocabulary Size Test (EVST) [4] test and a newly created XK_Lex [18], designed to make a more accurate measurement of vocabulary size. Results suggest that Saudi university students' vocabulary size is about 2000 to 3000 words on entry to university and around 5000 words nearer graduation.

In the article "Measuring the contribution of academic and general vocabulary knowledge to Learners' Academic Achievement" by Ahmed Masrai and James Milton demonstrates that the majority of the words from the AWL fall within the 3000 most frequent words that under graduates come across. Using a specifically created test of the AWL and a test of overall vocabulary size [1], the study demonstrates that the learning of the AWL appears to be strongly influenced by the frequency of these words in general corpora and that the AWL test very strongly resembles a test of overall vocabulary size. Knowledge of the AWL also adds marginally to the power of overall vocabulary size in explaining variance in grade point average (GPA) scores. This conclusion matches that of Townsend, Filippini, Collins, and Biancarosa [19], although the tests in the current study appear to have greater explanatory power [1]. They tried to prove that vocabulary size score of around 5000 words at about the time of graduation suggests learners will be competent rather than fluent users of English and if these learners are to become successful teachers of English as a foreign language, they will need language support and inservice training during their professional career.

\section{Aim of the study}

The researchers try to establish the importance of teaching academic vocabulary along with the technical or subject vocabulary to communicate with the world and students' difficulties and interests in learning vocabulary.

\section{Methodology}

The researchers did survey on 150 professional students of different branches of Engineering and found out the problems of using English language. A Vocabulary test on Technical and academic English is conducted and found the murkiness in mastering the vocabulary and its usage. Students were able to recognize the vocabulary related to their specific subject but failed in recognizing the connotative meanings of some general academic words. Another questionnaire has been given to find out the students' interest and methods of acquiring the vocabulary.

\section{Discussion}

New words are constantly being added to the vocabulary of English. Everyone feels comfortable to share one's ideas and opinions in one's mother tongue. One can write and speak in his mother tongue very easily. He will be so expressive and has the ability to argue and discuss on any topic that comes under the sun. At the same time he prefers to read in his mother tongue for an easy understanding. As long as English is not the compulsory language, none of us felt the intricacies involved in listening, speaking, reading and writing. Once, English language was one of the subjects 
to get the degree, but today, application of the language is very much essential for communication. The status of English language has been changed but the fear of using that language is still creating troubles for many. The students, who complete their schooling in English medium, are also hesitant to speak properly due to limited knowledge in vocabulary. This is so, because the teachers do not have any idea or training to teach vocabulary in a systematic way. The prescribed text books allot one or two exercises for acquiring vocabulary. Moreover, the Higher education believes that the students who join the engineering stream are good at language and give little importance to this English language curriculum. A multilingual country like India has to give importance to English as a communicative language in between the states. The Higher Education just can't ignore the importance of the language ability because this is going to be building block for the students to get employment. The students who come from rural areas are still need to improve their proficiency levels while using the language. The Higher Education needs to plan for revitalizing the English curriculum from theoretical to application of the language knowledge to be used for various purposes. Especially Vocabulary Instruction should not be limited to a few exercises. By and large vocabulary is developed with age and serves as a useful and fundamental tool for communication and gain knowledge in medium of communication. Knowledge of vocabulary enables language use. When it comes to the professional front, with limited academic vocabulary, the professionals face many troubles. Especially, the engineering students face it seriously during and after their campus recruitments. Acquiring an extensive vocabulary is one of the biggest challenges in second language acquisition. Because of the globalization, everyone is compelled to use English language for all practical purposes in one's professional or work front.

Apart from the distinctions between Academic and specific language, technical and non-technical vocabulary, or high and low-frequency words, the bare essentials of what one needs to be taught/known in terms of vocabulary are always the same: Form, Grammar, Collocations and Aspects of Meaning Now-a-days the professional education is everyone's choice but the competence levels and proficiency levels do not match accordingly. Generally, proficiency in any language begins with words and they in turn improve communicative ability. Through exposure to different situations and contexts the vocabulary of an individual will be strengthened. Since the Engineering curriculum has several branches and students are well- worse in the specific vocabulary which has a specific meaning $t$ times fail to understand or co-relate the meaning when it is used in general. The learning of vocabulary is a continuous process.

The researchers have picked some words peculiar to one's field of study for four years to the other professional students to pronounce and give meanings. Interesting results are found out.

Table 2. Examples of same words with different meaning in different fields.

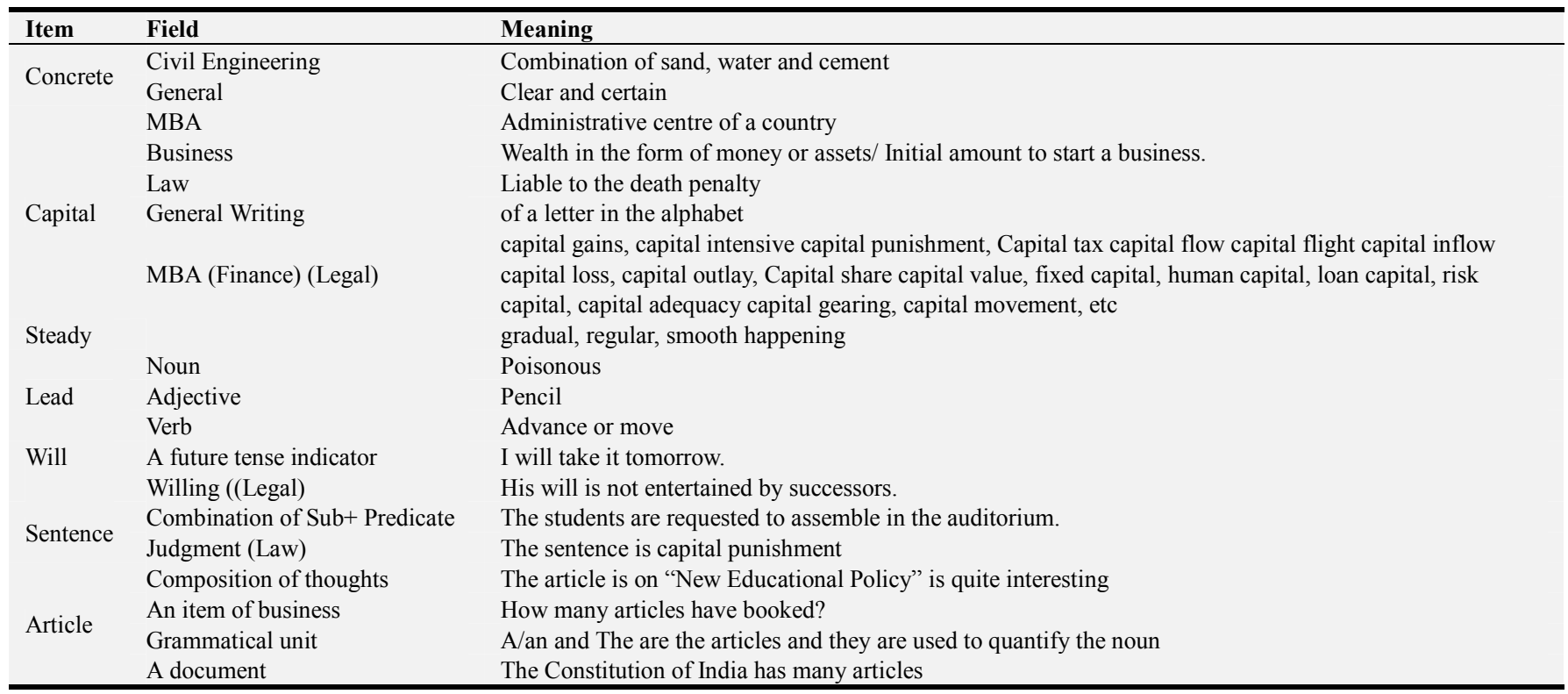

It's a unique feature that the words have several forms in its usage. It is not peculiar to English language. In every language some particular word can be used in different parts of speech with different meanings and in different connotations. The professional students who come from vernacular medium do not understand this feature and believes that English is a tough language and hard nut to be cracked. In multilingual countries like India, most of the students come from various linguistic backgrounds and have the fear of using the global language confidently. First, $60 \%$ of them join the professional degree from vernacular medium. It is obvious that they possess limited vocabulary. Secondly, because of the peer pressure, they don't want to express their inability to use English effectively. Thirdly, in the pretext of boring, they avoid the reading habit. Finally, at the time campus interviews, though they have the knowledge on the given topic, they fail to express themselves. This is all because of not having the proper vocabulary. In the 
professional education, it is believed that the students should concentrate on self development through self learning.

Academic Vocabulary includes Word Formation (Affixation) Synonyms, Antonyms, One-Word Substitutes, Phrasal Verbs, Idioms, Contronyms whereas Technical vocabulary deals with specific vocabulary related to their field. The professionals face difficulties in fixed word collocations, phrasal verbs, idioms, One-Word Substitutes. Nattinger and DeCarrico [6] have observed that a significant amount of the English language is made up of lexical phrases, which range from phrasal verbs (two or three words) to longer institutionalized expressions (Lewis, 1993, 1997).

Consider the following:

Word Formation: New words are derived by affixing the words or letter either at the beginning of the root word and letters at the end.

Example:

Word-Formation: Underdevelopment, Rehabilitation, Concretization, etc. Deriving new words through affixation

Synonyms: Often while speaking or writing, in the absence of a wide range of vocabulary, we tend to repeat the same words. Instead, we use the words that have more or less similar meaning. the expressions will have vividness. Having knpwledge in synonyms helps us to be more accurate in meaing. They also help us maintain brevity and effectiveness in communication.

Magnificent: Lexical meaning= Impressive or extremely beautiful

Connotative meanings: The coronation was a magnificent sight.

A magnificent Cathedral. (grandeur)

A magnificent poetry (sublime)

Synonyms: admirable, splendid, spectacular, impressive, striking, grandeur, etc.

Antonyms: unimpressive, unheroic, modest, feeble, etc

Antonyms not only help in broadening one's vocabulary but also help us to think critically, categorize, compare and contrast things and concepts.

Contronyms: There are certain words which can be their own opposites. Such words are known as Contronyms. Here are some words that are their own antonyms depending on the usage, etc.

Dust can mean to add 'fine particles' or 'to remove fine particles'

Left can mean both "remaining" and "depart"

Off can mean both activated and deactivated. E.g Set off: activated

Switch off: deactivated

Oversight means both 'watchful care and an inadvertent error

Screen can mean both 'to show' and 'hide'

Sanction can mean both a "penalty for disobeying a law" and official permission or approval for an action"

Phrasal verbs: The difficulty level increases when try to understand the phrasal verbs' usage in communication. The literal meaning of the phrasal verb lands us in trouble. Having knowledge in Idioms and Phrases is also a must for the professionals.

Put off - postpone, leave until a later time.

Put up with - to tolerate.

Put down - to insult.

Put on - to dress one.

Idioms: Idioms are an important part of everyday English. They come up all the time in both written and spoken English. Because idioms don't always make sense literally, one needs to familiarize oneself with the meaning and usage of each idiom. To mention a few:

Call it a day: Stop working on something

Cut somebody some slack: not to be critical

A blessing in disguise: a good thing that seemed bad at first

It's not rocket science: It's not complicated

On the ball: doing a job

A perfect storm: the worst possible situation

Hence, curriculum has to be redesigned to the vocabulary and prepare the students to use the language without much difficulty. First of all, the teachers and the taught must understand English is a language not a subject. For example, a country like India has several languages spoken and 18 languages are officially recognized. But the Northern part of India may not face the challenge because; instruction and exams can be done in Hindi medium. Whereas, the Southern part of India has five specific languages and instruction is done in English only. Until X standard, they learn the English as the third language but once they join +2 level, English language study becomes first language. The school education is offered in these states in Vernacular and English medium schools. The students who come from the vernacular medium feel difficulty to cope with the English language. English language in India is considered a link language. Hence, the language instruction should start from the primary level so that the students can understand and use the language and vocabulary can be acquainted without much difficulty.

Proficiency Level Tests

Since the English language has attained the global status, everyone is forced to improvise his language ability with a level of accuracy that transfers meaning in production and comprehension. By the 1990's, the idea of developing a CEFR was launched in 1991 to test the language proficiency. It aims at developing a comprehensive framework for language learning, teaching and assessment in general. The descriptors scaled by the CEFR are common for all. The students who get through these tests are recognized globally. Now it has become the need of the hour to be tested and proved according to the CEFR Proficiency levels. Apart from the content vocabulary, the professionals are required to develop language proficiency in general. Once the language proficiency tests like TOEFL, IELTS, etc are for those who aspire to pursue their post graduation courses but now the test scores are recognized by the industry. Unless the professionals master the vocabulary, they cannot comprehend and write in effective manner. The students who are qualified in these tests are not extraordinary in their expression. Taking the test mechanically will not help the students to become 
proficient user of the language. A test is conducted by the researchers to those students who have qualified B2 level to test their proficiency. The results show that their comprehensive levels and spoken abilities are normal. It is evident that the one who is good at the academic vocabulary can make use of myriad expressions so very easily. The industry needs the people who are good at English. The higher authorities need to concentrate on the pragmatic aspect of the language. The language classes in the professional colleges will not be taken seriously by the students for several reasons. One of the reasons to concentrate is the students do not feel something new or challenging in this language class. The digital media is open to all and they think and decide that they can master the language at the time of exams. On the other hand, the examination system is not testing the language ability of the students. Students' retention power is tested and passing the exam is a cake walk for the students. They get highest scores in their English Language Test but pathetically fail during their placement interviews. If they are asked to write or speak something on a given topic, the students miserably fail. For a placement interview, say for example, 2000 students appear from various branches; only 200-300 students will be placed. Exactly here, we need to concentrate on the problem of the students. Higher Education cannot overlook this problem, since any educational qualification should fetch a job at the end of the day. The job providers, Multi National Companies, look for those professionals who can perform. The students who are interested to continue their PG programs only can concentrate to develop vocabulary since the proficiency tests have to be cleared. But it will be the choice of a few. Hence, many students were neutral and undecided.

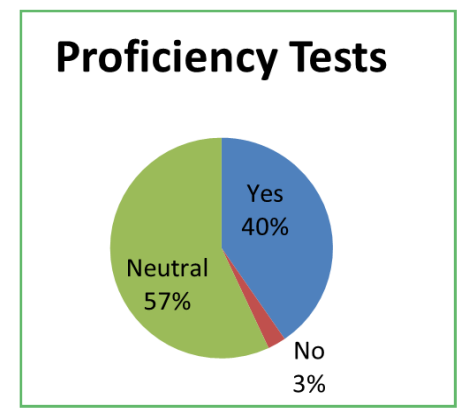

Figure 1. 151students responses to a question on Proficiency tests: Do they help in enhancing the vocabulary?

$57 \%$ students couldn't decide. $40 \%$ of the students were hopeful that proficiency tests will help to enrich vocabulary. Unfortunately, the students do not find the platform to exhibit their verbosity. Though the medium of instruction is in English, the teacher and the taught are comfortable to use their mother tongue for all practical purposes. The students do not find such an environment in their private universities where they can express and excel. The placement interviews gaze their communication skills at the outset because their employee should deal with the global clients.

Observations/Reasons

If we observe the reasons, they help the teachers and students to change their perspectives. Some teachers and Students were given the questionnaire to find out the reasons for not acquiring vocabulary. The observations are as follows:

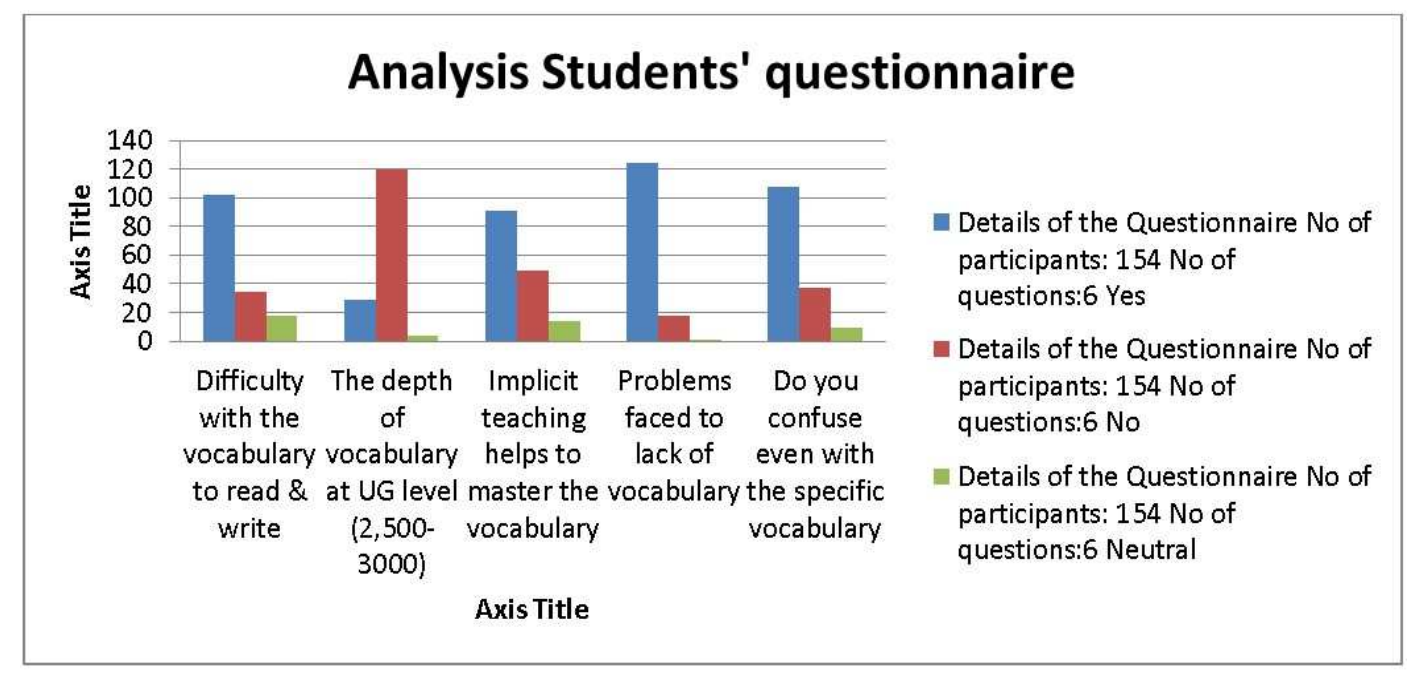

Figure 2. Analysis of students' questionnaire.

150 students were given a questionnaire on "Vocabulary acquisition." All these students are from professional colleges. Some of them are from English medium and some of them have come from vernacular mediums answered questions and suggested some strategies for vocabulary acquisition. Though all of them gave importance to reading to acquire vocabulary related to various fields, very few of them give importance to reading. $90 \%$ of them mentioned that they do not have the environment to discuss and analyze the books. $86 \%$ of the students are not aware of the proficiency level tests and the remaining mention that the tests will not improve their competencies as they do not find such an environment in their colleges. The complexity involved in the connotative meanings of certain words make them feel difficulty to use and understand the language. Students have even suggested three strategies to learn 
vocabulary. $27 \%$ of the students are interested to acquire mastery in vocabulary through Task- based, $50 \%$ of the students are interested in guess work and through context and the remaining are interested in concept of self interest. Out of 150 students, 110 students expressed their inability to understand academic vocabulary and feel difficulty to understand specific vocabulary related to other field.

During the survey many of the language teachers expressed the following reasons for not acquiring good amount of vocabulary by the students:

1. Majority of the teachers expressed that the time spent to teach vocabulary is not sufficient.

2. The English language teaching curriculum needs to be changed.

3. The schedule hours allotted to the language class is not sufficient for them to concentrate other than the prescribed.

4. The language teachers require some special training to teach Content Integrated Language Teaching that includes Vocabulary.

5. Different teachers adopt different ways of teaching.

6. The prescribed syllabus will not allow them to concentrate on teaching vocabulary

7. It is expected by many teachers that the students only inculcate the habit of acquiring the vocabulary through reading.

8. The students do not show interest in carrying the text books to the class

9. The present curriculum will examine the students' retention power rather than the ability to use the language.

The students, on the contrary, expressed different opinions through survey. To mention:

1. English language teachers concentrate to complete the syllabus.

2. The exercises that are given at the end of the text book are not challenging.

3. Majority of the students expressed that they could learn vocabulary with the help of glossary that used to be found in the beginning of every lesson.

4. Listening to English class is interesting but not interested in doing the exercises.

5. They do not show interest in reading because of the spellings, pronunciation and connotative meanings of some words. Hence, they fail to comprehend.

6. They never find the vocabulary teaching in their professional education

7. The proficiency test will be attempted by only few people because of several reasons.

Out of 154 students, 130 students (84\%) knew only reading helps them to enrich various situational vocabulary, but they do not show interest in reading. Hence, the curriculum developers are advised to design and prescribe literary texts to explore their vocabulary. If they are asked to describe any textual context either analytically and critically, they can explore their knowledge.

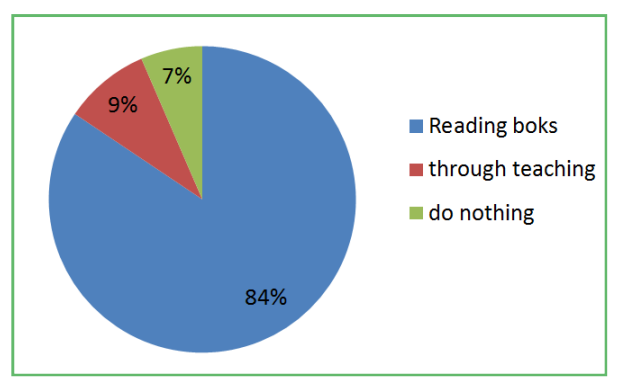

Figure 3. Results of a question on "Whether reading helps to improve vocabulary.

The authors try to present a thematic framework for the teachers to follow. The teachers of English language have three areas namely incidental learning, explicit instruction and independent strategy development to make use of to teach vocabulary effectively. Teachers will provide opportunities for extensive reading and listening in incidental learning. Text -based tasks are to be given to the students to read, understand and explain. Say for example, the teachers can introduce to write a script for knowing the specific vocabulary related to a particular branch of study. For example, they need to create a situation where the students are forced to think and learn to remember certain vocabulary For instance the role play on a dialogue with Travel agent makes them to learn the vocabulary peculiar to hospitality industry. Consider some of the buzz words used in Hospitality industry:

1. Itinerary means a detail description of the tour

2. PAX refers to number of persons going as a group

3. Modified American plan (MAP) - Meal plan that includes room and two daily meals, usually breakfast and dinner.

4. Rack rate - The price of a hotel prior to discount.

5. Ticket stock - Blank airline tickets.

6. Base fare - The cost of an airfare prior to addition of fees, taxes or surcharges.

7. CP: Continental Plan talks about Room with breakfast

8. AP: stands for American Plan which includes room with three meals a day

9. EP: stands for European Plan provides only room

10.GIT: Group Independent Traveler (person is added in)

11. FIT: Free Independent Traveller

Commutation, commute, errand, excursion, flight, hop, jaunt, junket, outing, sally, sortie, tour, Cruise, Sail, voyage, drive, ride, spin, grand tour, odyssey, pilgrimage, progress, quest, safari, hike, slog, tramp, walk, walkabout are certain words everyone of us need to know. If we have vocabulary bank communicating with others becomes very easy.

The curriculum designers have to concentrate to introduce vocabulary instruction through literary texts. Students must know figurative language to present their arguments. English Language paper too should concentrate on outcome-based education.

In Explicit instruction teachers analyze the words that learners need to know from the given text, and select those words which students come across them for the first time 
elaborating word knowledge, and developing fluency with known words.

The third category involves the students to guess the meaning of a word through context. The teachers should encourage the students to carry a dictionary to find out the meaning or allow them to use the mobile dictionary. Teaching vocabulary is a continuous process, The professional students are universal service providers. Hence, they must

1. Determine the part of speech of the unknown word.

2. Examine the immediate context and simplify it if necessary.

3. Look at the wider context. This entails examining the clause with the unknown word and its relationship to the surrounding clauses and sentences.

4. Guess the meaning of the unknown word.

5. Ensure that the guess is correct.

\section{Conclusion}

A rich vocabulary is an asset in any communication scenario- be written or spoken. If we have to understand and to be understood, we need to depend on the vocabulary that we use accordingly. The goal of vocabulary instruction is to help students learn the meanings of many words so they can communicate effectively and achieve academically. Effective vocabulary instruction requires educators to intentionally provide many rich, robust opportunities for students to learn words, related concepts, and their meanings. Students need strong instructional opportunities to build their personal warehouse of words, to develop deep levels of word knowledge, and acquire a toolbox of strategies that aids their independent word acquisition. Every teacher is an expert in designing the vocabulary teaching plan. Some of the strategies the authors of the paper use in the class are mentioned below:

1. Take the time to demonstrate the value of rich vocabulary

2. Create a word rich environment. Do not sympathize the vernacular medium students

3. Try to give the meaning through a situation to remember

4. Provide some of the words related to a particular field or branch and assign the tasks to perform or collect some more words to add

5. Engage the students in fun activities by using these words and derive different meaning through different accentuation

6. Give the challenge to use the words creatively by giving tasks related to different fields through roleplays

7. Associate the words with a situation to remember the pronunciation, spelling and meanings associated with that word

8. Write the list of words at the end of the class that are learned and assign the students to prepare a dialogue

9. Introduce Vocabulary games like Word Web, Spell-bee, what's the Good word?
10. Wall dictionaries enhance the vocabulary of the students.

11. Examine the students' vocabulary by giving situational role plays.

Finally training in the use of dictionaries is essential. Unfortunately, in most classrooms, very little time is provided for training in dictionary use [3]. In learners' attention should also be directed toward the value of good sentence examples which addition to learning the symbols and what information a dictionary can and cannot offer, learners may need extra practice for words with many entries. Furthermore, learners need to be taught to use all the information in an entry before making conclusions about the meaning of a word [5]. They provide collocation, grammatical, and pragmatic information about words. Finally, teachers should emphasize the importance of checking a word's original context carefully and comparing this to the entry chosen because context determines which sense of a word is being used. Unless curriculum prescribes, teachers do not concentrate much on vocabulary and students do not show interest in enriching their vocabulary. The Higher Education in countries like India must concentrate on revitalizing the concept of teaching vocabulary. The language English must be taught pragmatically.

\section{References}

[1] Ahmed Masrai and James Milton: Volume 19 No 3 November 2012. TESOL Arabia Perspective www.tesolarabia.org p13-18

[2] Hulstin. J., Hollander, M \& Greidanus T (1996). “Incidental Vocabulary Learning by Advanced Foreign Language Students: Dictionary Use and Reoccurrence of Unknown Words.” The Modern Language Journal, 80 p 327-339.

[3] Graves, M (1987) The Roles of Instruction in Fostering Vocabulary Development. In G Mckeown \& M. E. Curtis (Eds), "The Nature of Vocabulary Acquisition" 167-184 Hillsdale, N. J. Lawrence Erlbaum.

[4] Meara, P. \& Jones, G (1990) Euro Centre's Vocabulary Size Tests. User's Guide Zurich, Euro center.

[5] Laufer B. \& Hadar, L (1997). "Assessing the Effectiveness of Monolingual, Bilingual and Bilignualized Dictionaries in the Comprehension and Production of New Words". The Modern Language Journal, 81, 189-196.

[6] Nattinger. J. \&De Carrico, J. (1992). "Lexical Phrases and Language Teaching”. Oxford: Oxford University Press.

[7] Nation. I. S. P \& Coady J. (1988). Vocabulary and Reading. Vocabulary and Language Teaching. London: Longman.

[8] Summers, D (1988). The Role of Dictionaries in Language Learning: InR. Carter \& M Mc Carthy (Eds) Vocabulary and Language Teaching 111-125.

[9] Beck, Isabel L., Margaret G. McKeown, and Linda Kucan. (2002). "Bringing Words to Life: Robust Vocabulary Instruction". New York, NY: The Guilford Press.

[10] Nation, P. (Ed.). (1994). New ways in teaching Vocabulary. Alexandria, VA: TESOL. 
[11] Oxford, R. L. (1990). Language Learning Strategies: "What Every Teacher should know". Boston: Heinle and Heinle 323.

[12] Schmitt, N. (2000). Vocabulary in Language Teaching. Cambridge: Cambridge University Press.

[13] Fisher, D., \& Frey, N. (2008). Improving adolescent literacy: Content area strategies at work. Upper Saddle River, NJ: Pearson Education

[14] Horn burry, S. (2002). How to Teach Vocabulary? England: Pearson 1995). Vocabulary, Semantics, and Language Education. Cambridge: Cambridge University Press Education Limited.

[15] Ur, P., (1998). A Course in Language Teaching: Cambridge University Press.
[16] Walters, J. D. (2006). 'Methods of Teaching: Inferring Meaning from Context'. RELC Journal, 37 (2), pp. 176-190.

[17] Hyland K, Tse P. (2007). Is there an "Academic Vocabulary"? TESOL Quarterly, Vol. 41 (pgs 235-253).

[18] Al-Masrai, A. (2009). Measuring the English Vocabulary Size of Saudi University Students: Validating a New 10,000 Word Vocabulary Size Test. (Unpublished master's thesis). Swansea University, Swansea, UK.

[19] Townsend, D. Filippini, A., Collins, P., \& Biancarosa, G. (2012) Evidence for the Importance of Academic Word Knowledge for the Academic Achievement of Diverse Middle School Students. The Elementary School Journal, 112 (3), 497-518. 